Ethiopian Journal of Environmental Studies \& Management 8(5): 484 - 493, 2015.

ISSN:1998-0507

doi: http://dx.doi.org/10.4314/ejesm.v8i5.2

Submitted: November 28, 2014

Accepted: June 11, 2015

\title{
A COMPARISON OF GOOGLE EARTH EXTRACTED POINTS WITH GPS SURVEYED POINTS
}

\author{
*BUKA, L., MARUZIVA, R. AND NENHOWE, P. \\ Department of Geoinformatics and Surveying, University of Zimbawe, Harare
}

\begin{abstract}
Surveying has become the most effective way of taking measurement in or/and on the earth surface. There is an exponential rise in techniques of taking measurements on the earth for different reasons and purposes. Google Earth offers an open source service, easy to access and cost free image data that supports map interests and provides data which are crucial for engineering purposes. Google earth has become so popular not because of its high accuracy, but because it is easily accessible to anyone. Google Earth, virtual globe uses World Geodetic Coordinate System 1984 WGS84 as a global coordinate system. However, in this research, the transformations made from those data obtained using Global Positioning Systems (GPS) and those obtained from Google Earth were made and analyzed. The same points were uploaded to Global Positioning Systems and Google Earth for extraction of heights. The resultant coordinate generated contours obtained from both systems were analyzed and conclusions made. The height difference obtained from both system was $15.138 \mathrm{~m}$.
\end{abstract}

\section{Introduction}

Google Earth has increased in use and has become so popular to the extent of being used on smart phones for various purposes, among which are; armchair exploration, navigation, mapping, engineering works and planning purposes. A lot of survey work is likely to be done using Google Earth by virtue of a tool known as Surpac version 5,4 which has a Google Earth interface. Since June 2005 when it first appeared on the market, many people are using this Surpac version on their PCs, phones and even in vehicles. Currently, there are many tools which can be used to view Google Earth data. Virtual images in 3D can be obtained and viewed in an interactive manner in Google earth. A new tool, Surpac version 5.4, has been introduced and this has made it easy to access, extract points, doing measurements and displaying features on Google earth.
However, there are other methods of obtaining map data positional measurement such as conventional or modern land survey methods or global positional systems Global Positioning System (GPS) and remotely sensed imagery. GPS which is the modern technique that is applied widely in different areas of the fields of surveying and civil engineering is the method which was used in this research for evaluating the suitability of Google Earth generated heights for surveying purposes. The testing of the accuracy and the suitability of the heights and the generated or the ultimate contours produced from the heights obtained from Google Earth was of major concern for the research.

Surveying is the science of determining the position, in three dimensions, of natural and man-made features on or beneath the surface of the Earth. These features may be represented in analogue form as a

*Corresponding author: Buka, L.

Email: bukalt@yahoo.co.uk 
contoured map, plan, chart, or in digital form such as a digital ground model or an array of coordinates. Nowadays, they are many ways in which these measurements are made to model the ground or determining the positions, in three dimensions.

Some methods are strenuous whilst others are easy and flexible. The issue of carrying out surveys within the confines of the office has posed a number of questions to most land surveyors. The development of the new Surpac version with a Google Earth interface has increased awareness of how it can be used as a tool for accessing and manipulating data extracted from Google Earth for survey work. It is advantageous in cadastral and engineering work. Google Earth allows for the viewing of $2 \mathrm{D}$ or $3 \mathrm{D}$ colour satellite imagery for any point on the Earth, as well as being able to view galaxies and the ocean floors. The surface terrain imagery can be viewed at scales in the region of 1:2500 without any loss of detail quality. This figure can vary from region to region, but it is generally true for built up areas. Google Earth makes a useful visual display tool for SURPAC users when it is interfaced, or linked, with survey co-ordinates and/or image data.

Some of the advantages of Google Earth include:

$>$ Displaying the locations of trigonometrical beacons, town survey marks, points and lines from a survey plan or sheet for a selected area.

$>$ Displaying beacons and stations from a previous survey to help locate these points

$>$ Displaying user selected points in a coordinate file to help locate these points

$>$ Importing lines, paths or polygons created in Google Earth into Surpac.

\section{Google Earth}

Google Earth is a free computer program which uses a virtual globe to map the Earth using superimposed satellite and aerial imagery (Stillman, 2009). It is a virtual globe, map and geographical information program that was originally called Earth Viewer 3D, and was created by Keyhole, Inc., a Central Intelligence Agency (CIA) funded company acquired by Google in 2004 (Wikipedia). It uses the geographic coordinates system (latitude/longitude) for horizontal positioning of features on Earth using World Geodetic System 1984 (WGS84) datum based on the Geodetic Reference System 1980 GRS80, an ellipsoid that best fits the globe. On it, the Earth appears as if it is viewed from an elevated platform such as orbiting satellite or aircraft. It uses Geoidal model EGM96 (Earth Gravitational Model 1996) for heights (Stillman, 2009).

Resolution of satellite images used on Google Earth varies depending on the instrument used and the altitude of the satellites orbit. Satellite imagery is sometimes supplemented with aerial photography, which has a higher resolution, but is more expensive per square metre.

There are four types of resolution associated with satellite imagery and these are; spatial, spectral, temporal, and radiometric (Cambell, 2002). Some of the imagery used include:

$>$ SPOT 5 with an orbital altitude of $822 \mathrm{~km}$, which provides images with a resolution of 2.5 meters and a repeat cycle of 26 days.

$>$ Rapid Eye which has a constellation of 5 satellites containing identical multispectral sensors which are equally calibrated. It allows a large number of images to be collected per day and has a 24 hour repeat cycle. It operates at an altitude of $630 \mathrm{~km}$ above the earth's 
surface. (www.rapideye.com, June 2010)

Earth Resource Observation Satellites (EROS), which are lightweight, low, Earth orbiting, high resolution satellites designed for fast maneuvering between image targets. The satellites are deployed in a circular, sun synchronous, near polar orbit at an altitude of $510 \mathrm{~km}+/-40 \mathrm{~km}$.

$>$ Meteosat 2 a Geostationary weather satellite, also supplies imagery data. It operates on the first generation Meteosat 7, which is still active. (Wikipedia)

$>$ Geoeye 1 has the highest resolution of any commercial imaging system and is able to collect images with a ground resolution of 0,41 metres in the panchromatic mode. It collects multispectral or color imagery at I,65metresresolution.

\section{(www.geoeye.com)}

Digital Globe World View 2 satellite provides high resolution commercial satellite imagery with $0,46 \mathrm{~m}$ spatial resolution (panchromatic only). (Wikipedia) Google Earth file format is Keyhole Markup Language (KML) which is a format for modeling and storing geographic features such as points, lines, images, polygons, and models for display in maps or other applications. KML uses 3D geographic coordinates; longitude, latitude and altitude. The longitude, latitude components are as defined by the WGS84. The vertical component (altitude) is measured from the WGS84, EGM96 Geoid vertical datum. (Mohammed et al., 2013)

The types of projections used are Albers Equal Area Conic, Oblique Mercator, Lambert Conformal Conic projections and the Universal Transverse Mercator (UTM) is used in Polar regions. The Universal Polar Stereographic (UPS) grid system is used. Google Earth also uses the Simple Cylindrical Projection with WGS84 datum. In addition, it also uses the two generic types of coordinate systems; Cartesian and Curvilinear or Angular Coordinates. In Zimbabwe, surveys are based on the Cape Arc datum which originates from South Africa and the Gauss Lo system based on the Modified Clarke 1880 ellipsoid which is ideal for the Southern African region. The height systems used are the physical heights that are naturally linked to the equipotential surfaces and plumb lines of the earth's gravity field and thus follow curved paths. The other heights used are the ellipsoidal heights that ignore the earth's gravity field and thus use straight line paths. There are three types of natural or physical heights namely, dynamic heights, orthometric heights and normal heights (Heiskanem and Moritz, 1967).

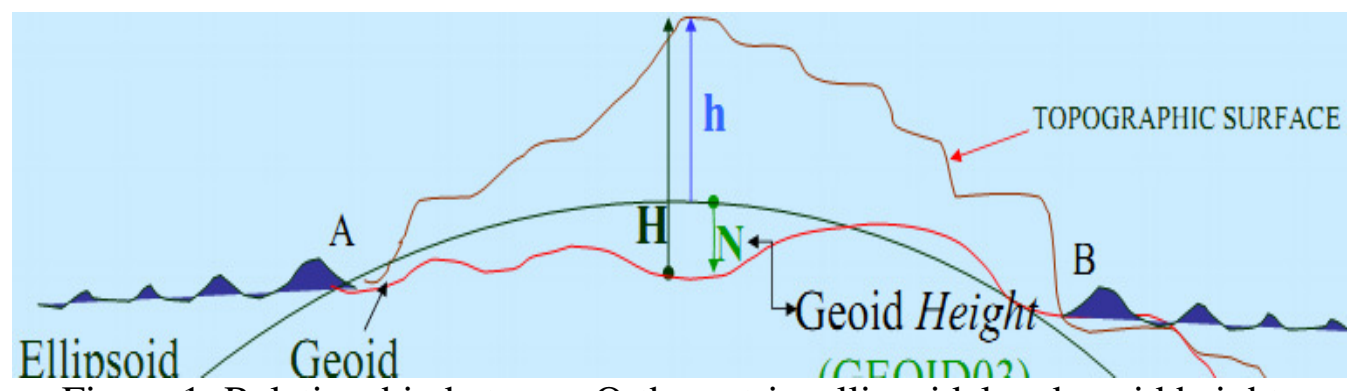

Figure 1: Relationship between Orthometric, ellipsoidal and geoid heights $\mathrm{H}=$ Orthometric Height $\mathrm{h}=$ Ellipsoidal Height $\mathrm{N}=$ Geoid Height $\mathrm{H}=\mathrm{h}-\mathrm{N}$ 


\section{Conversions and Geodetic Transformations}

There are a set of parameters which are used to convert from one coordinate system to another and to account for the location of the geometric centers of each reference ellipsoid with respect to the center of gravity of the Earth and in respect to each other. They also account for the difference in size and shape between the ellipsoids. The more general transformation used for such purposes is shown below

$$
\left(\begin{array}{l}
x \\
y \\
z
\end{array}\right)_{s}=\left(\begin{array}{l}
x \\
y \\
z
\end{array}\right)_{D}+\left(\begin{array}{l}
\Delta x \\
\Delta y \\
\Delta z
\end{array}\right)+\left(\begin{array}{l}
x \\
y \\
z \\
z
\end{array}\right)_{0}+\left(\begin{array}{ccc}
0 & w_{z} & -w_{y} \\
-w_{z} & 0 & \omega_{x} \\
y & -w_{x} & 0
\end{array}\right)\left(\begin{array}{l}
x \\
y \\
z
\end{array}\right)
$$

In this equation $\Delta \mathrm{L}$ is a scale difference, parameters $w x, w y, w z$ are rotations about the $\mathrm{X}, \mathrm{Y}, \mathrm{Z}$ datum axes which bring them parallel to the satellite axes. There are three shifts $(\Delta \mathrm{X}, \quad \Delta \mathrm{Y}, \quad \Delta \mathrm{Z}) \quad$ (Rapp, 1991). Different transformations have different degrees of accuracy and they are also dependent on the quality of control points. The different types of transformations are; the Bursa-Wolf Transformation Model, The Molodensky-Badekas Transformation Model and the Helmert Projection. The parameter values for the conversion are defined and as such do not lose accuracy and are reversible to get the same answer (Stillman, 2009).

\section{Transformations between Vertical Coordinate Reference Systems}

A vertical offset allows calculation of coordinates in the targeted vertical coordinate reference system by adding a correction parameter $\mathrm{A}$ to the coordinate values of the point in the source system: $\mathrm{X} 2$ $=\mathrm{X} 1+\mathrm{A} 1>2$, where:

$\mathrm{X} 2=$ value in the forward target vertical coordinate reference system.

$\mathrm{X} 1=$ value in the forward source vertical coordinate reference system.

A1 $>2$ is the offset to be applied for the transformation from CRS 1 to CRS 2. Its value for the forward calculation is the value of the origin of the source CRS 1 in the target CRS 2.

A further modification allows for source CRS axis, target CRS axis or offset to be in different units giving the general formulas:

for the forward transformation: $\quad \mathrm{X} 2=$ $\{\mathrm{m} *(\mathrm{X} 1 * \mathrm{U} 1)+(\mathrm{A} 1>2 * \mathrm{UA})\} / \mathrm{U} 2$

for the reverse transformation: $\mathrm{X} 1=$ $\{\mathrm{m} *[(\mathrm{X} 2 * \mathrm{U} 2)+(-\mathrm{A} 1>2 * \mathrm{UA})]\} / \mathrm{U} 1$

where U1 U2 and UA are unit conversion ratios for the two systems and the offset value respectively. $\mathrm{U}=$ [(factor b) / (factor c)] from the EPSG Dataset Unit of Measure table, populated with respect to the linear base unit, meter. U has a value of 0.3048 for the international foot. (Geomatics Guidance Note number 7, April 2012)

\section{Global Positioning System (GPS)}

There are many ways in which measurements can be made to model the ground or determine position in three dimensions. Examples of such methods of positional measurement are; conventional land survey methods and modern satellite based methods in the form of Global Navigational Satellite Systems which includes GALILEO, GLONASS and GPS among others.

The NAVSTAR GPS (NAVigation System with Time And Ranging Global Positioning System) is a satellite-based radio navigation system providing precise three-dimensional position, navigation, and time information to suitably equipped users. The system is continuously available on a world-wide basis, and is independent of meteorological conditions. GPS was developed in 1973 primarily as a military system with limited access to civil users. It has been used for the solution of geodetic problems since 1983.

The system nominally consists of 24 satellites placed in orbits of about 20 $200 \mathrm{~km}$ altitude above the earth's surface. The satellites are arranged in such a way that at least four satellites are 
simultaneously visible above the horizon anywhere on Earth, 24 hours a day. GPS is primarily a navigation system. The fundamental navigation principle is based on the measurement of so-called pseudo ranges between the user and four satellites.

Starting from the known satellite coordinates in a suitable reference frame the coordinates of the user antenna can be determined. From the geo-metrical point of view three range measurements are sufficient. A fourth observation is necessary because GPS uses the one-way ranging technique and the receiver clock is not synchronized with the satellite clock.

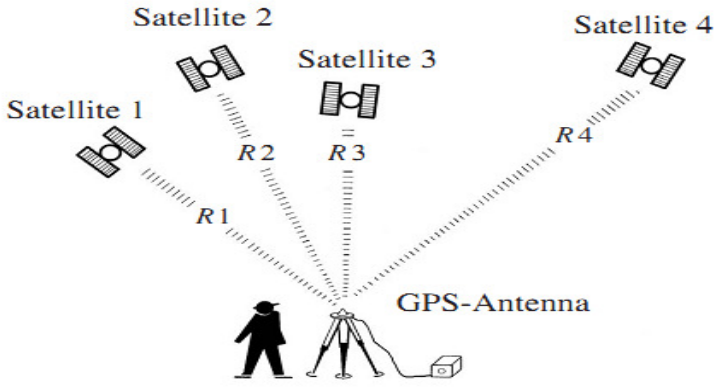

Figure 2: The principle applied by GPS (Seeber, 2003)

The GPS system can be broadly divided into three segments: the space segment, the control segment and the user segment (Schofield et al, 2007). GPS uses WGS84 for coordinates as the datum. WGS84 model is used to compute ranges from observer to satellite, and the subsequent position, based on all the relevant parameters supplied. The transformations of the WGS84 coordinates to local geodetic or plane rectangular coordinates and heights are made and Helmert transformation is applied. The translation, scale and rotational parameters between GPS and national mapping coordinate systems have been published (Schofield et al, 2007). Many GPS receivers can also measure the phase difference of satellite signals 19 and $24 \mathrm{~cm}$ carrier waves allowing for sub-centimeter distance resolution of ranges to the satellite (Navstar
Global Positioning System Surveying, 2003)

Surpac, AutoCAD and ArcGIS

Surpac is surveying software that was first developed in the mid-1970s and runs on different platforms such as on Microsoft Windows XP, Microsoft Windows Vista, Microsoft Windows 7 and Microsoft Windows 8 operating system (www.surpac.co.za). AutoCAD is a software for 2D and 3Dcomputer-aided design (CAD) and drafting. Since 2010, it has been used as a mobile web and cloud based application, currently marketed as AutoCAD 360 (Wikipedia). ArcGIS is Geographic Information System (GIS) software for working with maps and geographic information. It is used for creating and using maps, compiling geographic data, analyzing mapped information, sharing and discovering geographic information, using maps and geographic information in a range of applications and managing geographic information in a database.

\section{Methodology}

Identification of the site that was used for comparison and the evaluation of the heights obtained by Google Earth and by GPS was the first task. The identified site covering 10 hectares, had considerable variations in vegetation density and terrain levels and this site was in Borrowdale Brooke on the outskirts of the capital, Harare. Data searches were then conducted at the Department of the Surveyor-General to find the trigonometrical beacons within the vicinity of the site and four beacons namely 102/T, 124/T, 97/T, 99/T were selected and their coordinates obtained. A folder was created and in this folder all the trigs were uploaded with $\mathrm{X}$ as Northings and $\mathrm{Y}$ as Eastings and their heights. The collected data of the trigs were uploaded into the GPS control. GPS LEICA GS09 
and LEICA Geo Office 8.0 were used for the GPS field survey.

Trigonometric beacon 99/T was set as a reference point and Real Time Kinematic GP was used for the survey of the other trigs. The rest of the trigs were surveyed and information stored. After survey, transformations were done to determine the coordinate system. This coordinate system held all the parameters obtained during the transformation which is $\mathrm{dY}, \mathrm{dX}$ and $\mathrm{dZ}$. This was followed by relocation of the existing beacons and the new folder was created for storing this information. This folder was also used for storing grid points surveyed for the research area. Three stations STN1, STN2 and STN3 monumented using $12 \mathrm{~mm}$ iron pegs, were established using GPS for the use of a Total Station in highly vegetation area. Using Leica Geo Office 8.0 the surveyed points were downloaded and processed.

Three sets of points were collected for this research; 10 metre grid points surveyed by GPS and randomly selected points surveyed by a Total Station which was used in densely vegetated areas. The last set of points was extracted from Google Earth picked from the same locations that had been surveyed by the two methods mentioned above. Using a tool bar in AutoCAD, the points picked at the intersection of the grid lines at an interval of 10 meters and were stored. These points were uploaded to surpac and automatically $\mathrm{X}$ and $\mathrm{Y}$ coordinates were created. All the coordinated points together with surveyed points were edited, cleaned and then imported to LEICA Geo Office 8.0. A triangulation method of contour generation was used for coming up with a contoured map. The two results from Google Earth and GPS were opened and using some overlaying operators or functions, the differences and inconsistencies were determined.

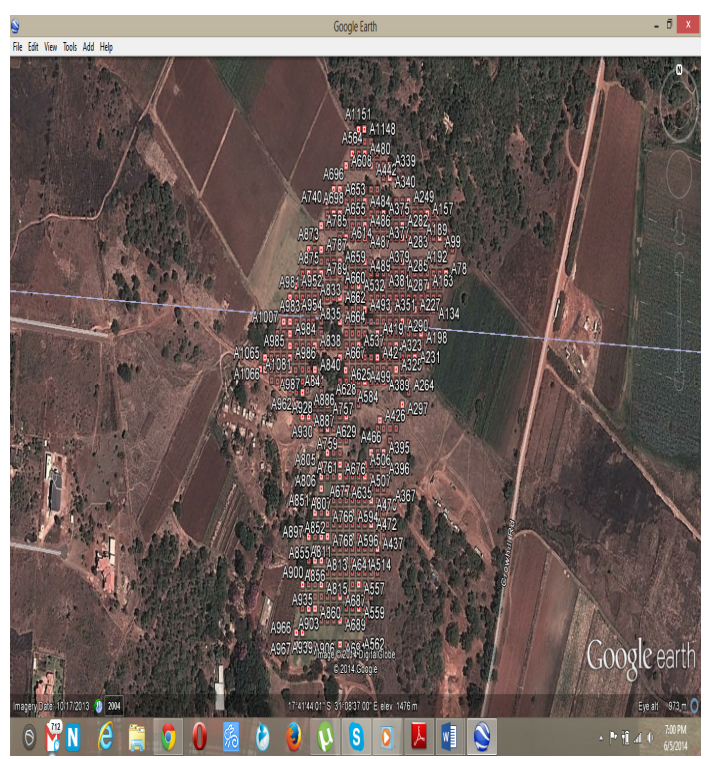

Figure 3: The selected Google Earth points

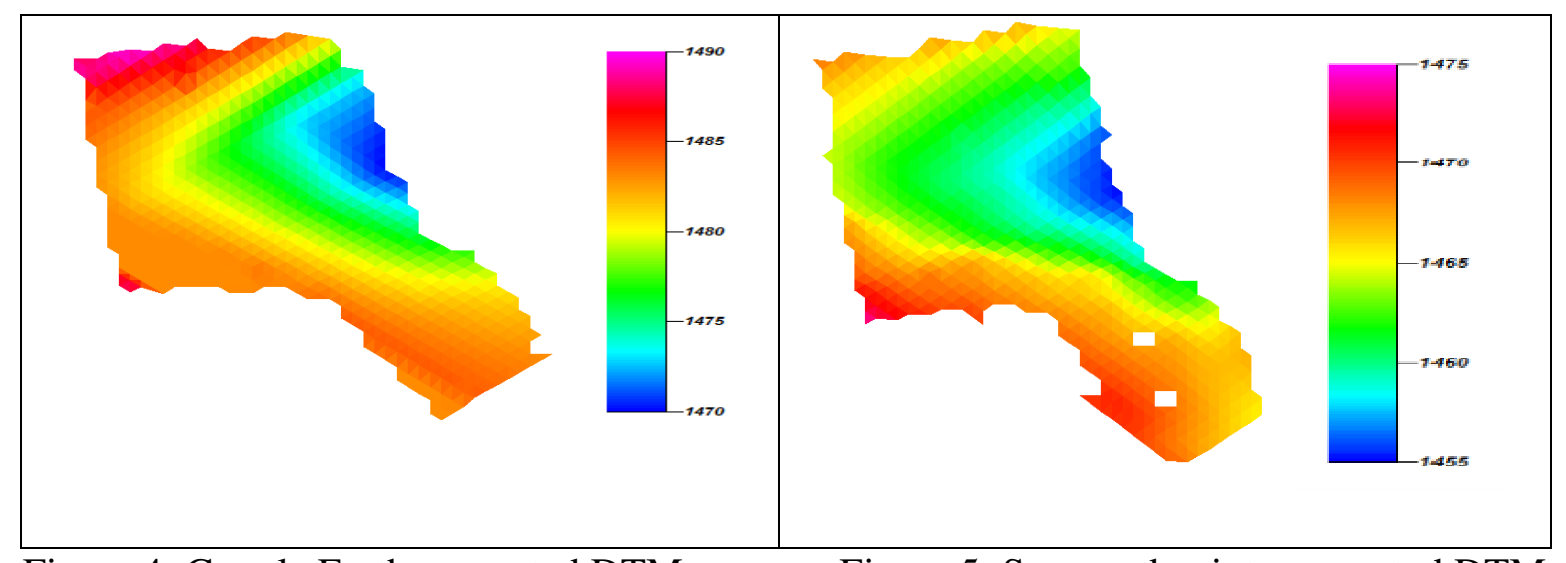

Figure 4: Google Earth generated DTM

Figure 5: Surveyed points generated DTM 


\section{Results}

Table 1: WGS84 coordinates of trigs used for the transformation

\begin{tabular}{|l|l|l|l|}
\hline Name & Latitude & Longitude & ellipsoidal height $(\mathrm{m})$ \\
\hline $104 \mathrm{~T}$ & $17^{\circ} 41^{\prime} 13.13160^{\prime \prime} \mathrm{S}$ & $31^{\circ} 10^{\prime} 51.35704^{\prime \prime} \mathrm{E}$ & 1518.3604 \\
\hline $124 \mathrm{~T}$ & $17^{\circ} 39^{\prime} 18.01431^{\prime \prime} \mathrm{S}$ & $31^{\circ} 07^{\prime} 02.79734^{\prime \prime} \mathrm{E}$ & 1550.2881 \\
\hline $97 \mathrm{~T}$ & $17^{\circ} 42^{\prime} 04.53971^{\prime \prime} \mathrm{S}$ & $31^{\circ} 10^{\prime} 15.24497^{\prime \prime} \mathrm{E}$ & 1554.4953 \\
\hline $99 \mathrm{~T}$ & $17^{\circ} 40^{\prime} 29.68687^{\prime \prime} \mathrm{S}$ & $31^{\circ} 08^{\prime} 42.41900^{\prime \prime} \mathrm{E}$ & 1529.163 \\
\hline
\end{tabular}

Table 2: local coordinate system of trigs used for the transformation

\begin{tabular}{|l|l|l|l|}
\hline Name & Latitude & Longitude & Orthometric heights $(\mathrm{m})$ \\
\hline $104 \mathrm{~T}$ & $17^{\circ} 41^{\prime} 03.03978^{\prime \prime} \mathrm{S}$ & $31^{\circ} 10^{\prime} 51.00478^{\prime \prime} \mathrm{E}$ & 1528.8052 \\
\hline $124 \mathrm{~T}$ & $17^{\circ} 39^{\prime} 07.92720^{\prime \prime} \mathrm{S}$ & $31^{\circ} 07^{\prime} 02.44349^{\prime \prime} \mathrm{E}$ & 1560.6662 \\
\hline $97 \mathrm{~T}$ & $17^{\circ} 41^{\prime} 54.44928^{\prime \prime} \mathrm{S}$ & $31^{\circ} 10^{\prime} 14.89433^{\prime \prime} \mathrm{E}$ & 1564.900 \\
\hline $99 \mathrm{~T}$ & $17^{\circ} 40^{\prime} 19.59789^{\prime \prime} \mathrm{S}$ & $31^{\circ} 08^{\prime} 42.06644^{\prime \prime} \mathrm{E}$ & 1539.500 \\
\hline
\end{tabular}

Transformation details

\begin{tabular}{lll}
\hline \multicolumn{2}{l}{$\begin{array}{l}\text { 3D-Helmert transformation } \\
\text { Number of common points: } \\
\text { Transformation model: }\end{array}$} & $\begin{array}{l}\text { 4 } \\
\text { Bursa-Wolf }\end{array}$ \\
\cline { 1 - 2 } & & \\
\hline No. & Parameter & Value \\
\hline 1 & Shift dX & $-80.3019 \mathrm{~m}$ \\
2 & Shift dY & $137.9372 \mathrm{~m}$ \\
3 & Shift dZ & $188.7774 \mathrm{~m}$ \\
4 & Rotation about X & $-5.21611 " ~$ \\
5 & Rotation about Y & $1.73986 "$ \\
6 & Rotation about Z & $6.89436 "$ \\
7 & Scale & $10.2638 \mathrm{ppm}$ \\
\hline
\end{tabular}

Residuals

Cartesian:

\begin{tabular}{llllll}
\hline System A & System B & Point type & $\mathrm{dX}[\mathrm{m}]$ & $\mathrm{dY}[\mathrm{m}]$ & $\mathrm{dZ}[\mathrm{m}]$ \\
$102 \mathrm{~T}$ & $102 \mathrm{~T}$ & Position + height & $0.0003 \mathrm{~m}$ & $0.0070 \mathrm{~m}$ & $-0.0045 \mathrm{~m}$ \\
$124 \mathrm{~T}$ & $124 \mathrm{~T}$ & Position + height & $-0.0186 \mathrm{~m}$ & $-0.0277 \mathrm{~m}$ & $0.0033 \mathrm{~m}$ \\
$97 \mathrm{~T}$ & $97 \mathrm{~T}$ & Position + height & $-0.0157 \mathrm{~m}$ & $-0.0282 \mathrm{~m}$ & $-0.0010 \mathrm{~m}$ \\
$99 \mathrm{~T}$ & $99 \mathrm{~T}$ & Position + height & $0.0340 \mathrm{~m}$ & $0.0489 \mathrm{~m}$ & $0.0021 \mathrm{~m}$ \\
\hline
\end{tabular}

The above transformation of occupied trigs was used to convert the Gauss Coordinate System generated points by AutoCAD for grid points and also for using the Total Station in densely vegetated areas of the project. It was also used for relocation of the parent property beacons. 
Table 3: the difference between grid points picked with GPS and Google Earth

\begin{tabular}{llllllll}
\hline Points & $\begin{array}{l}\text { GPS } \\
\text { height }(\mathrm{m})\end{array}$ & $\begin{array}{l}\text { GE height } \\
(\mathrm{m})\end{array}$ & $\begin{array}{l}\text { Difference } \\
(\mathrm{m})\end{array}$ & A197 & 1458.89 & 1473.774 & 14.884 \\
\hline A55 & 1464.645 & 1478.891 & 14.246 & A198 & 1458.161 & 1473.427 & 15.266 \\
A75 & 1465.041 & 1480.34 & 15.299 & A199 & 1457.731 & 1473.082 & 15.351 \\
A76 & 1464.458 & 1478.8 & 14.342 & A218 & 1465.707 & 1483.803 & 18.096 \\
A78 & 1462.67 & 1475.714 & 13.044 & A219 & 1464.602 & 1482.44 & 17.838 \\
A98 & 1466.011 & 1481.723 & 15.712 & A220 & 1463.983 & 1481.078 & 17.095 \\
A99 & 1464.755 & 1480.217 & 15.462 & A221 & 1463.347 & 1479.715 & 16.368 \\
A101 & 1463.628 & 1477.201 & 13.573 & A223 & 1462.191 & 1476.988 & 14.797 \\
\hline
\end{tabular}

Table 4: Difference between randomly picked points and GPS and Google Earth

\begin{tabular}{llllllll}
\hline Point & $\begin{array}{l}\text { GPS height } \\
(\mathrm{m})\end{array}$ & $\begin{array}{l}\text { GE height } \\
(\mathrm{m})\end{array}$ & $\begin{array}{l}\text { Difference } \\
(\mathrm{m})\end{array}$ & RN26 & 1456.6487 & 1473.769 & 17.1203 \\
\hline RN2 & 1461.9032 & 1477.384 & 15.4808 & RN27 & 1456.0289 & 1473.437 & 17.4081 \\
RN3 & 1461.3215 & 1477.278 & 15.9565 & RN28 & 1455.6321 & 1473.047 & 17.4149 \\
RN4 & 1461.5592 & 1477.407 & 15.8478 & RN29 & 1455.1739 & 1472.464 & 17.2901 \\
RN5 & 1462.1177 & 1477.333 & 15.2153 & RN30 & 1454.5332 & 1471.57 & 17.0368 \\
RN6 & 1462.7279 & 1477.228 & 14.5001 & RN31 & 1453.8334 & 1470.632 & 16.7986 \\
RN7 & 1462.7247 & 1476.959 & 14.2343 & RN32 & 1453.3691 & 1469.306 & 15.9369 \\
RN8 & 1462.8067 & 1476.703 & 13.8963 & RN33 & 1453.1202 & 1468.789 & 15.6688 \\
RN9 & 1462.0523 & 1476.119 & 14.0667 & RN34 & 1452.8979 & 1468.742 & 15.8441 \\
RN10 & 1462.084 & 1476.378 & 14.294 & RN35 & 1452.9615 & 1469.23 & 16.2685 \\
RN11 & 1460.8647 & 1476.666 & 15.8013 & RN36 & 1453.5087 & 1470.077 & 16.5683 \\
\hline
\end{tabular}

Table 5: SURPAC Trigonometrical Height Network Adjustment using Least Squares

\begin{tabular}{lllllllll}
\hline & \multicolumn{3}{c}{ Observed } & & & & Calc. & \\
\hline & & Vertical & Instr & target & Horiz & height & height & Height \\
\hline From & to & Angle & Height & height & dist. & difference & adjust & difference \\
\hline STN1 & STN2 & $89: 19: 31$ & 1,554 & 2,256 & 90,37 & 0,363 & $-0,293$ & 0,070 \\
STN1 & STN3 & $89: 01: 23$ & 1,554 & 2,256 & 67,50 & 0,449 & $-0,286$ & 0,163 \\
STN1 & A589 & $90: 18: 13$ & 1,554 & 2,256 & 29,54 & $-0,858$ & 0,000 & $-0,858$ \\
STN1 & A546 & $90: 18: 13$ & 1,554 & 2,256 & 33,13 & $-0,878$ & 0,000 & $-0,878$ \\
STN1 & A505 & $91: 58: 50$ & 1,554 & 2,256 & 39,03 & $-2,051$ & 0,000 & $-2,051$ \\
STN1 & A504 & $92: 15: 37$ & 1,554 & 2,256 & 46,91 & $-2,553$ & 0,000 & $-2,553$ \\
STN1 & A545 & $90: 48: 17$ & 1,554 & 2,256 & 42,13 & $-1,294$ & 0,000 & $-1,294$ \\
\hline
\end{tabular}

Table 6: The difference between randomly picked points and Total Station and Google Earth Points

\begin{tabular}{llll}
\hline POINT NAME & $\begin{array}{l}\text { TOTAL STN GRID } \\
\text { PICKED HEIGHTS }\end{array}$ & $\begin{array}{l}\text { GE GRID PICKED } \\
\text { HEIGHTS }\end{array}$ & HEIGHT DIFFERENCES \\
\hline A505 & $1,464,416$ & $1,478,583$ & 14,167 \\
A546 & $1,465,589$ & $1,479,139$ & 13,550 \\
A589 & $1,465,609$ & $1,479,688$ & 14,079 \\
A711 & $1,465,732$ & $1,480,420$ & 14,688 \\
\hline
\end{tabular}




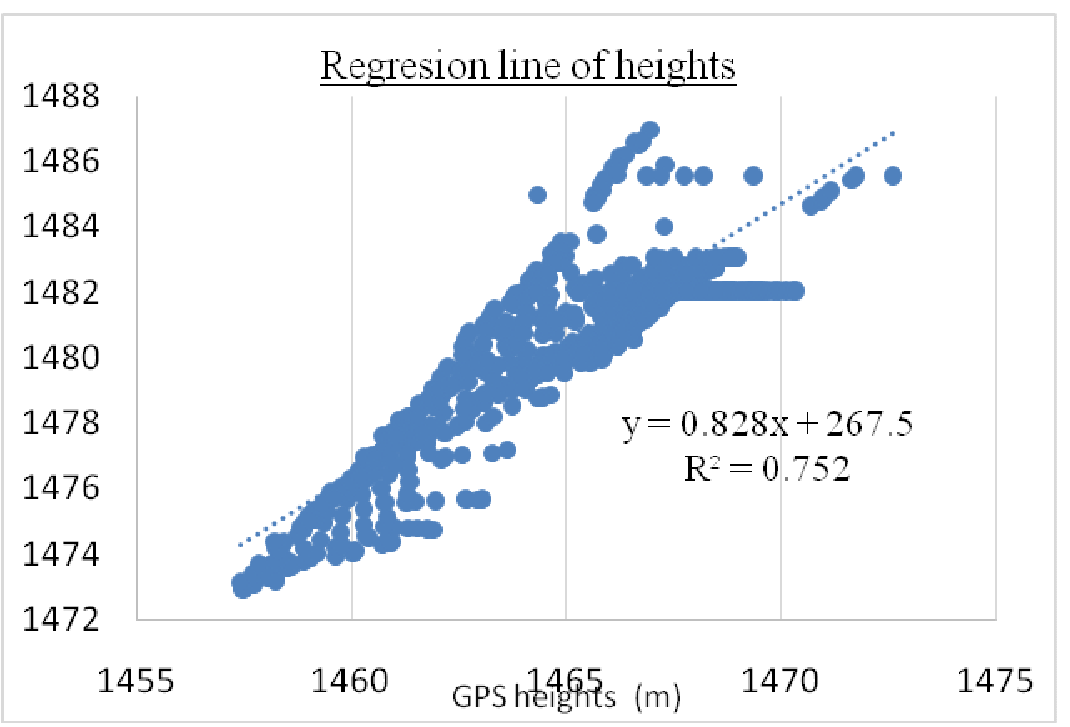

Figure 6: The regression analysis of grid picked points from table 3

From the transformation carried out (bursa wolf), the shift, scale factor and rotation values were high but the residuals of the transformed trigonometrical beaconss had reasonable values, only beacon 99/T had the highest residuals on both the $\mathrm{X}$ and $\mathrm{Y}$ axes and $102 \mathrm{~T}$ had the smallest residual. The effect of transformation error was neglected for the points picked using a Total Station since there were only 15 points affected. The height difference obtained from the results of the two systems GPS and Google Earth was 15,138meters on average for both methods (Random and Grid system). From the 1170 points obtained from both systems, point RN226 had the least height difference of 12,7342m and point A339 had the greatest difference of $19,84 \mathrm{~m}$. The height difference for heights obtained using the conventional method (Total Station) against heights extracted from Google Earth was less than that obtained using GPS. An average of $14.347 \mathrm{~m}$ was obtained compared to $15.138 \mathrm{~m}$ obtained from GPS. This was because the portion covered by the points with the Total Station was small and the issue of tilt was insignificant. For the points under trees or vegetation, the height difference was as constant as that from open ground. As illustrated above for the grid points, there are similarities and differences notably the maximum height for the GPS was $1475 \mathrm{~m}$ and that of Google Earth was $1490 \mathrm{~m}$ giving a height difference of $15 \mathrm{~m}$. The maximum height for the GPS was $1475 \mathrm{~m}$ and that for Google Earth was $1490 \mathrm{~m}$ giving a height difference of $15 \mathrm{~m}$.

\section{Conclusion}

The accuracy of the height information extracted from Google Earth was on average $1.305 \mathrm{~m}$. This makes it possible for surveyors to obtain topographic information and contour maps at 1:50 000 scale and smaller. The average of the differences in heights was $15.138 \mathrm{~m}$. Google Earth gave the actual configuration of the terrain as it appeared and despite the height differences, there were consistencies for all the heights extracted.

For other survey work, a constant of $15.138 \mathrm{~m}$ could be subtracted from Google Earth heights which would result in heights with similar precision and accuracy as those obtained from conventional surveys. The heights obtained from the Google Earth could be used for planning purposes, 
generating Digital Terrain Models and for survey work that did not require much accuracy with the only exception being highly vegetated areas.

\section{References}

April, R. (2012). Geomatics Coordinate Conversions and Transformations including Formulas. (7).

Campbell, J.B. (2002). Introduction to Remorte Sensing, pp. 1-621

Clynch, J.R. (2006). Earth Coordinates, pp.1-18.

Featherstone, W.E. (2010). Height Systems and Vertical Datums, A review in the Australian context. pp.1-31.

Geomatics Guidance Note, number 7, part 2, April 2012

Heiskanem, M. (1967). Physical Geodesy, pp $1-420$

Mathew, N.O. (2009). Coordinate Systems and Transformation Parameters in Local Map Production, Updates and revisions in Nigeria, FIG working week.

Mohammed, N.Z., Ghazi, A. and Mustafa, H.E. (2013). Positional Accuracy Testing of Google Earth, pp.6-9.
Navstar Global Positioning System Surveying (2003

Rapp R.H. (1984). Geometric Geodesy, Volume 1

Rapp, R.H. (1993). Separation between reference surfaces of selected vertical datums, Bulletin geodesique, Ohio State University, Columbus, USA

Seeber, G. (2003). Satellite Geodesy, Berlin, New York: Walter de Gruyter. Available at: http://www.degruyter.com/view/book s/9783110200089/9783110200089/97 83110200089.xml.

Stillman, D.M. (2009). Plotting surveying data in Google Earth, 36, pp.1-6.

Schofield, W. and Breach, M. (2007). Engineering Surveying, $6^{\text {th }}$ Edition, pp 1-637

Schofield, W. (1984). Engineering Surveying, Volume 1, \#rd Edition.

www.degruyter.com/view/books/97831102 00089/9783110200089/97831102000 89.xml.

www.geoeye.com, June, 2010

www.rapideye.com, June 2010

www.surpac.co.za 